\title{
Effect of Ki-67 assessment in the distribution of breast cancer subtypes: Evaluation in a cohort of Latin American patients
}

\author{
ALEJANDRO YÁBAR ${ }^{1}$, ROSA MELÉNDEZ ${ }^{2}$, SILVIA MUÑOZ ${ }^{3}$, HUGO DENEO $^{4}$, \\ JIMENA FREIRE ${ }^{4}$, VIVIANA DOMÍNGUEZ ${ }^{4}$, ROBERTO M. CARRASCO-NAVARRO ${ }^{5}$, \\ MARIA E. DIAZ ${ }^{5}$ and RAÚL E. VELARDE-LÓPEZ ${ }^{5}$
}

\author{
${ }^{1}$ Department of Pathology, Edgardo Rebagliatti Martins National Hospital; ${ }^{2}$ Department of Pathology, \\ Guillermo Almenara Irigoyen National Hospital; ${ }^{3}$ Department of Pathology, Alberto Sabogal National Hospital, \\ Lima, Perú; ${ }^{4}$ Laboratory of Pathological Anatomy, Nacional Cancer Institute, \\ Montevideo, Uruguay; ${ }^{5}$ F. Hoffmann-La Roche Ltd., Lima, Perú
}

Received September 22, 2016; Accepted February 3, 2017

DOI: $10.3892 / \mathrm{mco} .2017 .1185$

\begin{abstract}
Breast cancer (BC) is a heterogeneous disease composed of four main subtypes with distinct clinical and epidemiological features. Although several reports have described the distribution of $\mathrm{BC}$ subtypes in Latin America, the majority of them have not included the cellular marker, $\mathrm{Ki}-67$, in the immunohistochemical (IHC) panel. The aim of the present study was to describe the distribution of $\mathrm{BC}$ subtypes in a cohort of Latin American women using an IHC panel with $\mathrm{Ki}-67$. A prospective cohort of 580 patients in three centers of Peru (the Hospital Nacional Edgardo Rebagliatti Martins, the Hospital Nacional Guillermo Almenara Irigoyen, the Hospital Nacional Alberto Sabogal, Lima) and one in Uruguay (Instituto Nacional del Cáncer, Montevideo) were evaluated. BC phenotypes were classified according to an IHC panel: Estrogen receptor (ER), progesterone receptor (PgR), HER2 and Ki-67. Silver in situ hybridization was used when the HER2 status, as determined by IHC, was equivocal. The associations between the $\mathrm{BC}$ phenotypes and their clinicopathological features were evaluated. ER was positive in $65 \%$ of the cases ( $\mathrm{n}=377)$, and PgR in 50\% ( $\mathrm{n}=203)$. In total, 79.1\% $(\mathrm{n}=459)$ were HER2-negative, $19.8 \%(\mathrm{n}=115)$ were HER2positive and $1 \%(\mathrm{n}=6)$ had an equivocal status. With respect to Ki-67, $44.7 \%$ of the patients exhibited staining in $>14 \%$ of the tumor cells $(\mathrm{n}=259)$. The distribution of subtypes was as follows: Luminal A, 31.9\% ( $\mathrm{n}=183)$; luminal B, 35\% ( $\mathrm{n}=201)$; HER 2, $12.1 \%(n=70)$; and triple-negative, 20.9\% $(n=120)$. When Ki-67 was not included in the panel, the frequency of luminal A was $41.1 \%$ and luminal B, 25.8\% (9.2\% of the cases were misclassified). Ki-67 was most highly expressed
\end{abstract}

Correspondence to: Dr Alejandro Yábar, Department of Pathology, Edgardo Rebagliatti Martins National Hospital, 490 Rebagliati Avenue, Jesus María, Lima 11, Perú

E-mail: ayabar25@gmail.com

Key words: breast neoplasm, immunohistochemistry, breast cancer subtypes, epidemiology in triple-negative and HER2 tumors. Inclusion of $\mathrm{Ki}-67$ in the IHC panel to assign subtypes revealed a higher frequency of luminal B tumors than was reported previously for Latin American women with $\mathrm{BC}$, whereas the distribution of triple-negative and HER2 tumors were similar to that previously reported. In conclusion, these results demonstrated that excluding Ki-67 from the panel of IHC markers may lead to an underestimation of the rates of luminal B tumors.

\section{Introduction}

Breast cancer (BC) is the most common malignancy in women around the world, with $\sim 1.7$ million new cases reported per 100,000 women every year (1). Although the prognosis of $\mathrm{BC}$ continues to improve due to advances in systemic therapies, there are disparities between countries according to their development index and between ethnic groups $(2,3)$. Approximately 140,000 Latin American women develop BC each year, representing a high burden of disease, with a higher incidence in young women compared with that observed in other regions of the world $(1,4)$.

The seminal work of Perou, Sorlie et al (5-7) demonstrated that $\mathrm{BC}$ is a heterogeneous disease with three main driver mutations, involving the estrogen receptor 1 (ESR1), progesterone receptor (PGR) and HER2 genes, leading to a classification of the breast tumors into four main subtypes: The luminal A, luminal B, basal, and HER2-enriched subtypes. Molecular subtyping is based upon the evaluation of mRNA profiling with microarrays or an analysis of 50 genes by reverse transcription-polymerase chain reaction, a procedure that is not suitable for routine use. Later studies identified surrogate subtypes, based on the immunohistochemical (IHC) assessment of the estrogen receptor (ER), PgR and HER2 genes (8). Further studies demonstrated that the cellular marker, Ki-67, is useful to distinguish between luminal subtypes $(9,10)$. The majority of the luminal B tumors may lack the expression (or amplification) of HER2, leading to a misclassification of a luminal A subtype. For this reason, Ki-67 is an important marker to identify appropriately surrogates of the BC subtypes (9). 
There are different distribution patterns of the subtypes across the ethnic groups. Several studies have demonstrated a higher incidence of the triple-negative subtype in Hispanic women and women of African descent compared with Caucasian women (11-13). Although several previous reports have described the frequencies of $\mathrm{BC}$ phenotypes in certain Latin American countries, the majority of them did not include the use of Ki-67 in the IHC panel to discriminate luminal B tumors from luminal A ones. The aim of the present study was to determine the effect of $\mathrm{Ki}-67$ on the distribution of $\mathrm{BC}$ phenotypes defined in a prospective cohort of Latin American women.

\section{Patients and methods}

Study design. The present study is a prospective evaluation in patients diagnosed with BC between 2012 and 2013 in three hospitals from Peru and one from Uruguay [the Hospital Nacional Edgardo Rebagliatti Martins, the Hospital Nacional Guillermo Almenara Irigoyen, the Hospital Nacional Alberto Sabogal (all located in Lima) and the Instituto Nacional del Cáncer in Montevideo].

Patient selection and sample size. Patients diagnosed with BC between 2012 and 2013 were enrolled. Exclusion criteria included a lack of pathological material for IHC analysis, or the patient refusing at any time to participate in the present study.

Biomarker evaluation. Evaluation of all the biomarkers was performed in tumors that has been fixed in $10 \%$ neutral formalin and were paraffin-embedded. Samples taken from biopsies ( $\mathrm{n}=248,42.8 \%)$, lumpectomies $(\mathrm{n}=177,30.5 \%)$, and mastectomies $(\mathrm{n}=155,26.7 \%)$ were evaluated. A set of $5-\mu \mathrm{m}$ tissue slides were cut and loaded on to electrically charged Superfrost Plus ${ }^{\mathrm{TM}}$ (Thermo Fisher Scientific, Inc., Waltham, MA, USA) glass slides for IHC or silver in situ hybridization (SISH) staining.

$I H C$. The following primary antibodies were employed in the present study: Anti-ER (alpha; clone 1D5), anti-progesterone receptor (PR) (PgR636), anti-Ki-67 (MIB-1), and PATHWAY ${ }^{\circledR}$ anti-HER2 (clone 4B5). Anti-ER, anti-PR, and anti-Ki-67 antibodies were obtained from Agilent Technologies, Inc. (Dako Products; Agilent Technologies, Inc., Santa Clara, CA, USA) and PATHWAY ${ }^{\circledR}$ anti-HER 2 was obtained from Roche (Roche Diagnostics GmbH, Mannheim, Germany). Evaluation of the level of ER and PR was performed according to American Society of Clinical Oncology (ASCO)/College of American Pathologists (CAP) ER and PgR guideline recommendations (14). HER2 evaluation was performed according to the ASCO/CAP guidelines, and scored in four categories (HER2 $0^{+}$, HER $21^{+}$, HER2 $2^{+}$and HER2 $3^{+}$) (15). Antigen retrieval and IHC processing was performed according to manufacturer's protocols, and all IHC procedures were performed in local laboratories. The IHC evaluation for HER2 was performed using the Ventana BenchMark Classic Automated system (Ventana Medical Systems, Oro Valley, AZ, USA). If any sample was identified as being HER2 equivocal (HER2 $2^{+}$), a SISH evaluation was subsequently performed.
Silver in situ hybridization (SISH). HER2 determination by SISH was performed by using the Ventana HER2 dual-color ISH assay automated staining system, performed in the Ventana BenchMark Classic Automated system (Ventana Medical Systems). Slides were pretreated with Cell Conditioning Solution (CC2; pH 6.0, Ventana Medical Systems), followed by protein digestion with ISH protease (for $12 \mathrm{~min}$ ) and subsequent incubation with the INFORM HER2 Dual ISH DNA PROBE cocktail (Vendana Medical Systems) for 6 h. Detection was performed using an ultraView SISH DNP Detection kit, according to the manufacturer's protocol. Silver precipitation was deposited in the nuclei, and single copies of the HER2 gene were visualized as single black dots and single copies of chromosome 17 [the chromosome enumeration probe 17 (CEP)] as red dots on the same slide. The slides were then counterstained using haematoxylin II and a bluing reagent. The SISH staining was carried out using the Ventana BenchMark Classic Automated system (Ventana Medical Systems). The numbers of chromosome 17 CEP and HER2 signals were counted in 20 non-overlapping nuclei per core. Samples with HER2/17 CEP $<1.8$ were considered negative, whereas those cases with HER 2/17 CEP $>2.2$ were considered to be positive, and cases with HER2/17 CEP between 1.8-2.2 were considered to be equivocal.

Definition of BC phenotypes. Luminal tumors were defined by the expression of any of the hormonal receptors. Among this group, luminal A tumors were classified as negative for HER2 where $\mathrm{Ki}-67$ expression was low (with $<14 \%$ tumor cells being positive), whereas luminal B tumors had high Ki-67 expression ( $\geq 14 \%$ tumor cell positivity). The HER2 phenotype was positive for HER2, and negative for hormonal receptors. Tumors with negative status for HER2 and hormonal receptors were classified as being triple-negative.

Statistical analysis. As the present work did not include hypothesis testing, sample size calculations were not performed. Descriptive data are presented, and associations between categorical data were evaluated using the Chi-square or Fisher's test. Associations between categorical data and quantitative variables were evaluated with the Student's t-test or an analysis of variance (one-way ANOVA) test. $\mathrm{P}<0.05$ was considered to indicate a statistically significant difference.

Ethical considerations. The present study was approved by the local institutional review boards (IRBs) and the Ministry of Health (MoH). Patients were enrolled in this study after having signed a form to give their informed consent.

\section{Results}

Patient characteristics. In total, 580 out of 599 patients screened for the present study met the eligibility criteria. A total of 19 patients refused to participate or had important data missing in the clinical record, and were excluded. Accrual of patients across the centers was as follows: 398 patients (68.6\%) from the Hospital Nacional Edgardo Rebagliatti Martins (Lima, Peru); 93 (16\%) from the Hospital Nacional Guillermo Almenara Irigoyen (Lima, Peru); 70 (12.1\%) from the Hospital Nacional Alberto Sabogal Sologuren (Lima, Peru); and 19 
Table I. Hormonal receptors and HER2 and their association with clinicopathological parameters.

\begin{tabular}{|c|c|c|c|c|c|c|c|c|c|}
\hline & \multicolumn{3}{|c|}{ ER status } & \multicolumn{3}{|c|}{ PR status } & \multicolumn{3}{|c|}{ Her2 status } \\
\hline & Neg & Pos & P-value & Neg & Pos & $\mathrm{P}$-value & $\mathrm{Neg}$ & Pos & P-value \\
\hline $\begin{array}{l}\text { Age at diagnosis } \\
(\text { mean } \pm \mathrm{SD})\end{array}$ & $56.7 \pm 12.4$ & $58.9 \pm 13.3$ & 0.066 & $58.9 \pm 12.2$ & $57.4 \pm 13.8$ & 0.176 & 58.8 & 55.8 & 0.017 \\
\hline Age group (years) & & & 0.280 & & & 0.004 & & & 0.056 \\
\hline$<40$ & $19(9.4 \%)$ & $24(6.4 \%)$ & & $17(5.9 \%)$ & $26(9.0 \%)$ & & $31(6.8 \%)$ & $11(9.6 \%)$ & \\
\hline $40-49$ & $40(19.7 \%)$ & $82(21.8 \%)$ & & $46(15.9 \%)$ & $76(26.2 \%)$ & & $100(21.8 \%)$ & $21(18.3 \%)$ & \\
\hline $50-59$ & $61(30.0 \%)$ & $92(24.4 \%)$ & & $89(30.7 \%)$ & $64(22.1 \%)$ & & $109(23.7 \%)$ & $42(36.5 \%)$ & \\
\hline $60-69$ & $46(22.7 \%)$ & $92(24.4 \%)$ & & $77(26.6 \%)$ & $61(21.0 \%)$ & & $109(23.7 \%)$ & $28(24.3 \%)$ & \\
\hline \pm 70 & $37(18.2 \%)$ & $87(23.1 \%)$ & & $61(21: 0 \%)$ & $63(21.7 \%)$ & & $110(24.0 \%)$ & $13(11.3 \%)$ & \\
\hline Menopausal status & & & 0.961 & & & 0.011 & & & 0.703 \\
\hline Premenopausal & $36(18.8 \%)$ & $64(17.8 \%)$ & & $38(13.8 \%)$ & $62(22.5 \%)$ & & $79(18.2 \%)$ & $19(17.1 \%)$ & \\
\hline Perimenopausal & $21(19.9 \%)$ & $40(11.1 \%)$ & & $27(76.4 \%)$ & $34(12.3 \%)$ & & $50(11.5 \%)$ & $10(9 \%)$ & \\
\hline Postmenopausal & $135(70.3 \%)$ & $256(71.1 \%)$ & & $211(76.4 \%)$ & $180(65.2 \%)$ & & $306(70.3 \%)$ & $82(73.9 \%)$ & \\
\hline Unknown & 11 & 17 & & 14 & 14 & & 24 & 4 & \\
\hline Nuclear grade & & & $<0.001$ & & & $<0.001$ & & & $<0.001$ \\
\hline Grade 1 & 0 & $18(4.8 \%)$ & & $6(2.1 \%)$ & $12(2.1 \%)$ & & $18(3.9 \%)$ & 0 & \\
\hline Grade 2 & $61(30 \%)$ & $279(74 \%)$ & & $129(44.5 \%)$ & $211(72,8 \%)$ & & $287(62.5 \%)$ & $48(41.7 \%)$ & \\
\hline Grade 3 & $142(70 \%)$ & $80(21.2 \%)$ & & $155(53.4 \%)$ & $67(23,1 \%)$ & & $154(33.6 \%)$ & $67(58.3 \%)$ & \\
\hline Histological grade & & & $<0.001$ & & & $<0.001$ & & & $<0.001$ \\
\hline Well-differentiated & $20(9.9 \%)$ & $97(25.8 \%)$ & & $45(15.6 \%)$ & $72(24.9 \%)$ & & $108(23.6 \%)$ & $6(5.3 \%)$ & \\
\hline $\begin{array}{c}\text { Moderately } \\
\text { differentiated }\end{array}$ & $79(39.1 \%)$ & $231(61.4 \%)$ & & $131(45.3 \%)$ & $179(61.9)$ & & $250(54.6 \%)$ & $58(50.9 \%)$ & \\
\hline Poorly differentiated & $103(51 \%)$ & $48(12.8 \%)$ & & $113(45.3 \%)$ & $38(13.1 \%)$ & & $100(21.8 \%)$ & $50(43.9 \%)$ & \\
\hline Unknown & 1 & 1 & & 1 & 1 & & 1 & 1 & \\
\hline Lymphovascular invation & & & 0.03 & & & 0.025 & & & 0.129 \\
\hline Present & $141(69.5 \%)$ & $226(60.1 \%)$ & & $197(67.9 \%)$ & $170(58.8 \%)$ & & $299(65.3 \%)$ & $66(57.4 \%)$ & \\
\hline Absent & $150(30.5 \%)$ & $62(39.9 \%)$ & & $93(32.1 \%)$ & $119(41.2 \%)$ & & $159(34.7 \%)$ & $49(42.6 \%)$ & \\
\hline Unknown & 0 & 1 & & 0 & 1 & & 1 & 0 & \\
\hline $\mathrm{Ki}-67$ value & & & $<0.001$ & & & 0.045 & & & $<0.001$ \\
\hline Low & $65(32 \%)$ & $194(51.5 \%)$ & & $117(40.3 \%)$ & $142(49 \%)$ & & $224(48.8 \%)$ & $32(27.8 \%)$ & \\
\hline High & $138(68 \%)$ & $183(48.5 \%)$ & & $173(59.7 \%)$ & $148(51 \%)$ & & $235(51.2 \%)$ & $83(72.2 \%)$ & \\
\hline
\end{tabular}

ER, estrogen receptor PR, progesterone receptor; neg, negative; pos, positive; SD, standard deviation.

(3.3\%) from the Instituto Nacional del Cancer (Montevideo, Uruguay).

The median age was 58 years (range: 27-90 years). With regard to the menopausal status, $18.1 \%$ were premenopausal $(n=100) ; 11.1 \%$ were postmenopausal $(n=61)$, and $70.8 \%$ $(n=552)$ were postmenopausal. In 28 cases, the menopausal status was unknown (Table I).

Histopathological features. With regard to the histological subtypes, the carcinoma ductal NOS was present in $78.3 \%$ of cases $(n=454)$, followed by lobular carcinoma, $10.9 \%$ $(\mathrm{n}=63)$; mucinous carcinoma, 3.6\% $(\mathrm{n}=21)$; mixed carcinoma, $1.2 \%(\mathrm{n}=7)$; metaplastic carcinoma, $1.2 \%$; and others, $4.8 \%$. Histological grade 1 was present in $20.2 \%$ ( $n=117)$; grade 2 was present in $53.6 \%(n=310)$ and grade 3 in $26.1 \%(n=151)$. Two cases were of unknown histological grade. With regard to the nuclear grade, $3.1 \%(n=18)$ had grade $1 ; 58.6 \%(n=340)$ had grade

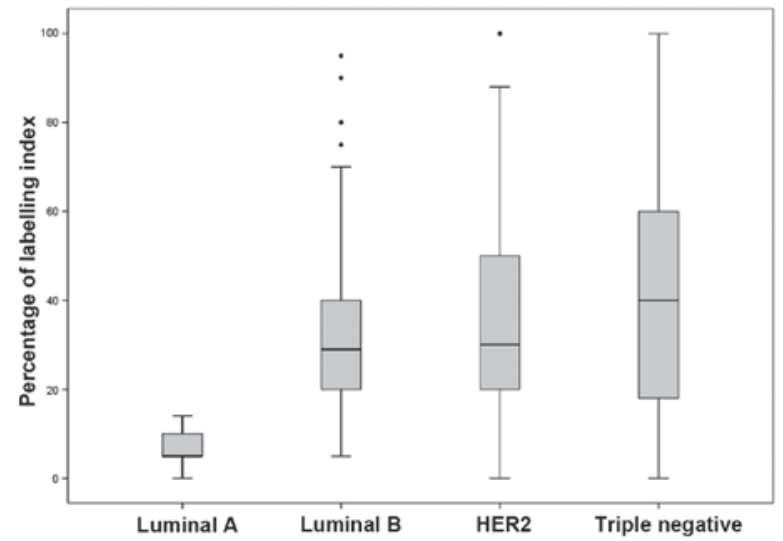

Figure 1. Box plot of Ki-67 LI in different phenotypes. Significant differences were identified in the post hoc analysis for the luminal A vs. luminal B, luminal A vs. HER2, luminal A vs. triple-negative, and luminal B vs. triple-negative groups. 
Table II. Clinicopathological characteristics of the phenotypes of breast cancer.

\begin{tabular}{|c|c|c|c|c|c|c|}
\hline Characteristic & All patients & Luminal A & Luminal B & HER 2 & Triple Negative & P-value \\
\hline Number (n) & $574^{\mathrm{a}}$ & $183(31.9 \%)$ & $201(35.0 \%)$ & $70(12.1 \%)$ & $120(20.7 \%)$ & \\
\hline Age at diagnosis & & & & & & \\
\hline$($ mean $\pm \mathrm{SD})$ & $58.1 \pm 13$ & $58.8 \pm 58.8$ & $56.4 \pm 11.9$ & $55.4 \pm 11.5$ & $58.4 \pm 12.7$ & 0.175 \\
\hline Age group (years) & & & & & & 0.003 \\
\hline$<40$ & $42(7.3 \%)$ & $6(3.3 \%)$ & $21(10.4 \%)$ & $7(10 \%)$ & $8(6.7 \%)$ & \\
\hline $40-49$ & $121(21.1 \%)$ & $40(21.9 \%)$ & $44(21.9 \%)$ & $13(18.6 \%)$ & $24(20 \%)$ & \\
\hline $50-59$ & $151(26.3 \%)$ & $35(19.1 \%)$ & $58(28.9 \%)$ & $27(38.6 \%)$ & $31(25.8 \%)$ & \\
\hline $60-69$ & $137(23.9 \%)$ & $46(25.1 \%)$ & $47(23.4 \%)$ & $14(20 \%)$ & $30(25 \%)$ & \\
\hline \pm 70 & $123(21.4 \%)$ & $56(30.6)$ & $31(15.4 \%)$ & $9(12.9 \%)$ & $27(22.5 \%)$ & \\
\hline Menopausal status & & & & & & 0.074 \\
\hline Premenopausal & $98(17.1 \%)$ & $21(12 \%)$ & $46(24.1 \%)$ & $13(19.1 \%)$ & $18(16.1 \%)$ & \\
\hline Perimenopausal & $60(10.5 \%)$ & $25(14.3 \%)$ & $16(8.4 \%)$ & $8(11.8 \%)$ & $11(9.8 \%)$ & \\
\hline Postmenopausal & $388(67.6 \%)$ & $129(73.7 \%)$ & $129(67.5 \%)$ & $47(69.1 \%)$ & $83(74.1 \%)$ & \\
\hline Unknown & 28 & 8 & 10 & 2 & 8 & \\
\hline Nuclear grade & & & & & & $<0.001$ \\
\hline Grade 1 & $18(3.1 \%)$ & $10(5.5 \%)$ & $8(4.0 \%)$ & 0 & 0 & \\
\hline Grade 2 & $335(58.46 \%)$ & $148(80.9 \%)$ & $131(65.2 \%)$ & $18(25.7 \%)$ & $38(31.7 \%)$ & \\
\hline Grade 3 & $221(38.5 \%)$ & $25(13.7 \%)$ & $62(30.8 \%)$ & $52(74.3 \%)$ & $82(68.3 \%)$ & \\
\hline Histological grade & & & & & & $<0.001$ \\
\hline Well-differentiated & $114(19.9 \%)$ & $66(36.3 \%)$ & $30(14.9 \%)$ & $3(4.3 \%)$ & $15(12.5 \%)$ & \\
\hline Moderately differentiated & $308(53.8 \%)$ & $104(57.1 \%)$ & $132(65.7 \%)$ & $27(39.1 \%)$ & $45(37.5 \%)$ & \\
\hline Poorly differentiated & $150(26.2 \%)$ & $12(6.6 \%)$ & $39(19.4 \%)$ & $39(56.5 \%)$ & $60(50.0 \%)$ & \\
\hline Unknown & 2 & 1 & 0 & 1 & 0 & \\
\hline Lymphovascular invation & & & & & & 0.001 \\
\hline Present & $365(63.7 \%)$ & $122(67.0 \%)$ & $114(56.7 \%)$ & $38(54.3 \%)$ & $91(75.8 \%)$ & \\
\hline Absent & $208(36.3 \%)$ & $60(33.0 \%)$ & $87(43.3 \%)$ & $32(45.7 \%)$ & $29(24.2 \%)$ & \\
\hline Unknown & 1 & 1 & 0 & 0 & 0 & \\
\hline ER status & & & & & & $<0.001$ \\
\hline Positive & $372(64.8 \%)$ & $179(97.8 \%)$ & $193(96 \%)$ & 0 & 0 & \\
\hline Negative & $202(35.2 \%)$ & $4(2.2 \%)$ & $8(4 \%)$ & $70(100 \%)$ & $120(100 \%)$ & \\
\hline PR status & & & & & & $<0.001$ \\
\hline Positive & $286(49.8 \%)$ & $132(72.1 \%)$ & $154(76.6 \%)$ & 0 & 0 & \\
\hline Negative & $288(50.2 \%)$ & $51(27.9 \%)$ & $47(23.4 \%)$ & $70(100 \%)$ & $120(100 \%)$ & \\
\hline HER2 status & & & & & & $<0.001$ \\
\hline Positive & $115(20.0 \%)$ & 0 & $45(22.4 \%)$ & $70(100 \%)$ & 0 & \\
\hline Negative & $459(80 \%)$ & $183(100 \%)$ & $156(77.6 \%)$ & 0 & $120(100 \%)$ & \\
\hline
\end{tabular}

${ }^{a}$ Only cases with subtype determined were included. ER, estrogen receptor PR, progesterone receptor; SD, standard deviation.

2 and $38.3 \%$ (222) had grade 3. Vascular or lymphatic invasion was present in $63.3 \%$ of cases $(n=367)$ (Table II). Information concerning the nodal status and metastases was not included due to the large number of patients who were referred to other centers following the primary diagnosis or surgery (note that the Peruvian Hospitals involved in the present study belong to the Social Security System, EsSalud Perú).

IHC biomarker status and HER2 SISH evaluation. The ER was positive in $65 \%(n=377)$ of cases, while the $P R$ was positive in $50 \%(n=203)$ of them. With regard to HER2 status, $59.1 \%$ $(n=343)$ of the cases were scored $0 ; 16.7 \%(n=97)$ were scored
$1+; 6.7 \%(\mathrm{n}=39)$ were scored $2^{+}$and $17.4 \%(\mathrm{n}=101)$ were scored as $3+$. A total of 38 out 39 cases scored as $2+$ were evaluated using SISH, and the results were negative in $50 \%(n=19)$ of cases, positive in $36.8 \%(n=14)$ and equivocal in $13.2 \%(n=5)$ of them. In total, $79.1 \%(n=459)$ were HER2-negative, $19.8 \%$ $(n=115)$ were HER2-positive and $1 \%(n=6)$ were equivocal for HER2. The median index for Ki-67 expression in tumor cells was $27 \%$ in total, and $55.3 \%(n=321)$ and $44.7 \%(n=259)$ had low Ki-67 and high Ki-67 expression, respectively.

Distribution of BC phenotypes. A total of 574 cases were evaluable for phenotype determination (note that the phenotype 
Table III. Distribution of BC phenotypes among different Hispanic countries.

\begin{tabular}{|c|c|c|c|c|c|c|c|c|}
\hline Authors & Country & $\mathrm{n}$ & Markers & Luminal A (\%) & Luminal B (\%) & HER2 (\%) & Triple-negative (\%) & Refs. \\
\hline The present study & Peru/Uruguay & 574 & $\begin{array}{l}\text { ER, PR, HER2, } \\
\text { Ki-67 }\end{array}$ & 31.9 & 35.0 & 12.1 & 20.9 & \\
\hline Vallejos et al & Peru & 1,198 & ER, PR, HER2 & 49.3 & 13.2 & 16.2 & 21.3 & $(13)$ \\
\hline Alarcon-Rosaz et al & Peru & 142 & ER, PR, HER2 & 79.4 & 0 & 0 & 20.6 & $(20)$ \\
\hline Camejo et al & Uruguay & 169 & ER, PR, HER2 & 58.0 & 8.0 & 18.0 & 16.0 & $(21)$ \\
\hline Abuchacra et al & Argentina & 365 & ER, PR, HER2 & 76 & 6.0 & 3.0 & 15.0 & $(22)$ \\
\hline Carvalho et al & Brazil & 5,665 & $\begin{array}{l}\text { ER, PR, HER2, } \\
\text { Ki-67 }\end{array}$ & 27.7 & 47.6 & 8.9 & 15.8 & $(18)$ \\
\hline de Macêdo Andrade et al & Brazil & 269 & $\begin{array}{l}\text { ER, PR, HER2, } \\
\text { Ki-67 }\end{array}$ & 23.8 & 44.6 & 14.5 & 17.1 & $(23)$ \\
\hline Martinez et al & Mexico & 416 & ER, PR, HER2 & 57.9 & 22.6 & 0 & 19.5 & (24) \\
\hline Perez-Sanchez et $a l^{\text {a }}$ & Mexico & 478 & ER, PR, HER2 & 17.4 & 51.3 & 8.0 & 22.6 & $(25)$ \\
\hline
\end{tabular}

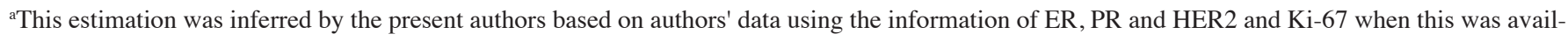
able. ER, estrogen receptor PR, progesterone receptor.

could not be determined in 6 cases due to the HER2 equivocal status). When Ki-67 was included in the classification, distribution of subtypes was: Luminal A, 31.9\% ( $\mathrm{n}=183)$; luminal B, $35 \%(n=201)$; HER2, $12.1 \%(n=70)$ and triple-negative, $20.9 \%$ $(n=120)$ (Table II). In the luminal B phenotype, 148 cases were HER2-positive and 53 cases were HER2-negative (Table I).

Effect of $\mathrm{Ki}-67$ on the distribution of $\mathrm{BC}$ subtypes. In the absence of $\mathrm{Ki}-67$ in the BC subtype classification, the frequency of luminal A was $41.1 \%$ (overestimated in $9.2 \%$ of cases) and of luminal B, $25.8 \%$ (underestimated in $9.2 \%$ of cases). With regard to $\mathrm{Ki}-67$ expression, there were differences (according to the ANOVA analysis) in the luminal A vs. luminal B $(\mathrm{P}<0.001)$, luminal A vs. HER2 $(\mathrm{P}<0.001)$, luminal A vs. triple-negative $(\mathrm{P}<0.001)$, and luminal $\mathrm{B}$ vs. triple-negative $(\mathrm{P}=0.001)$ groups (Fig. 1).

Correlation among ER, PgR and HER2 status and clinicopathological variables. A significant association was identified between PgR status and the age group, and this association was revealed by comparing the means of positive and negative HER2 tumors (HER2-positive patients tended to be younger). The same association was observed for the menopausal status. ER-negative, PR-negative and HER2-positive cases presented higher frequencies of tumors with nuclear grade $3(\mathrm{P}<0.001)$ and poorly differentiated tumors $(\mathrm{P}<0.001)$. Lymphovascular invasion was identified most commonly in ER-negative and PR-negative tumors ( $\mathrm{P}=0.03$ and 0.025 , respectively). High $\mathrm{Ki}-67$ expression occurred most frequently in ER-negative, PR-negative and HER2-positive tumors $(\mathrm{P}<0.001, \mathrm{P}=0.045$ and $<0.001$, respectively) (Table I). The Ki-67 status was highly correlated with the histological grade, where 30.8, 54.2 , and $77.5 \%$ of cases were $\mathrm{Ki}-67$ positive for histological grades I, II and III, respectively $(\mathrm{P}<0.001)$.

Correlation of BC phenotypes with clinicopathological features. Significant associations were identified between the age groups and phenotypes, where luminal A patients were more likely to be older $(\mathrm{P}=0.003)$. With regard to the nuclear grade, patients with triple-negative and HER2 tumors were more likely to have grade 3 tumors $(\mathrm{P}<0.001)$ (Table II).

\section{Discussion}

$\mathrm{BC}$ is a malignancy with a high incidence in Latin American women, and it presents with different epidemiological characteristics in comparison with Caucasian, Asian or African ethnic groups (1).

Although several reports have previously described BC subtypes according to IHC classification, there is a lack of information about the distribution of molecular BC subtypes. Although the IHC subtype classification is important, the molecular approach itself may be able to identify subtle levels of mRNA expression of the HER2 or hormonal receptors in triple-negative patients, providing opportunities for targeted therapy in this group of patients (16).

The distribution of tumors positive for ER, PgR or HER2 may change on the basis of ethnicity. Chu et al (17), in a study from 2002 that evaluated 123,732 patients, did not identify any variation in the incidence of ER-positive or PgR-positive cases among different ethnic groups, although differences in incidence were identified according to the age group and clinical stage.

As shown in Table III, it seems that ancestry has an important role in BC subtype distribution. A report in 2014 by Carvalho et al (18) based on the Brazilian population revealed a regional variation in $\mathrm{BC}$ distribution, predominantly in luminal B tumors; an association of luminal B tumors with regions of European ancestry (south and southeast) was also observed, whereas the northern and central eastern regions presented high frequencies of triple-negative tumors when the comparison was made.

In the present study, the frequency of positive cases for ER, PgR and HER2, and the association with clinicopathological variables, was revealed to be similar to rates previously described in the literature $(8,13,17)$.

In the present study, it was possible to determine the BC phenotype in 574 out of 580 patients, where $13.2 \%$ of patients had an equivocal result for HER2 following SISH analysis, a higher proportion compared with that reported previously (4.9\%) in studies involving SISH analysis (19). 
A previous report by Vallejos et al (13) in 2010 described a frequency of $49.13 \%$ of luminal A tumors; $13.2 \%$ of luminal B tumors; $16.2 \%$ of HER2 tumors; and $21.3 \%$ for triple-negative tumors; another study by Alarcon-Rosas et al (20) in 2011 described an incidence of triple-negative $\mathrm{BC}$ of $20.6 \%$. In the present prospective analysis, in studies that reported cases of Hispanic patients, it was observed that the proportion of triple-negative $\mathrm{BC}$ was similar among different countries.

High rates of triple-negative $\mathrm{BC}$ in Latin American women lead to a higher frequency of interval cancers (Table III) $(18,21-25)$. It adds a challenge for the cancer control programs that are based on the use of mammograms for $\mathrm{BC}$ screening. The recent guidelines from the American Cancer Society suggested that screening for BC should be initiated for women at the age of 45 years; however, based on the high frequency of triple-negative tumors, consideration should be given to commencing screening for $\mathrm{BC}$ in Latin American women at a younger age (26).

The distribution of luminal tumors has been revealed to be variable among different reports in Hispanic cohorts: This could be explained according to the different methodologies that have been used to determine luminal A or B tumors, in comparison with triple-negative or HER2 ones. In the cohort in the present study, it was possible to recognize that $9.2 \%$ of luminal B tumors were confusable with luminal A tumors if $\mathrm{Ki}-67$ had not been included in the analysis.

Cheang et al (9) demonstrated that $13.25 \%$ is the best index cut-off point to distinguish luminal B from luminal A tumors. Inclusion of Ki-67 in the panel of IHC biomarkers is important to discriminate luminal B tumors that lack expression of HER2. Distinction between these two groups is important due to their different prognostic characteristics. The risk of recurrence is two times greater for luminal B tumors compared with luminal A tumors (10). In conclusion, a misclassification of $9.2 \%$ of the cases of luminal tumors was produced in the absence of $\mathrm{Ki}-67$ in the IHC panel. These findings have corroborated previously reported data on the distribution of HER2- and triple-negative tumors in Latin American patients with BC.

\section{Acknowledgements}

The present study was supported by an Academic Grant of Roche, Peru. Note that R.M.C., M.E.D. and R.E.V. are employees of Productos Roche del Perú, Lima, Peru.

\section{References}

1. Ferlay J, Soerjomataram I, Ervik M, Dikshit R, Eser S, Mathers C, Rebelo M, Parkin DM, Forman D and Bray F: GLOBOCAN 2012 v1.0, Cancer Incidence and Mortality Worldwide: IARC CancerBase No. 11. Lyon, France. http://globocan.iarc.fr. Accessed October 5, 2014.

2. Ooi SL, Martinez ME and Li CI: Disparities in breast cancer characteristics and outcomes by race/ethnicity. Breast Cancer Res Treat 127: 729-738, 2011.

3. Justo N, Wilking N, Jönsson B, Luciani S and Cazap E: A review of breast cancer care and outcomes in Latin America. Oncologist 18: 248-256, 2013.

4. Villarreal-Garza C, Aguila C, Magallanes-Hoyos MC, Mohar A, Bargalló E, Meneses A, Cazap E, Gomez H, López-Carrillo L, Chávarri-Guerra Y, et al: Breast cancer in young women in Latin America: An unmet, growing burden. Oncologist 18: 1298-1306, 2013.
5. Perou CM, Sørlie T, Eisen MB, van de Rijn M, Jeffrey SS Rees CA, Pollack JR, Ross DT, Johnsen H, Akslen LA, et al: Molecular portraits of human breast tumours. Nature 406: 747-752, 2000.

6. Sørlie T, Perou CM, Tibshirani R, Aas T, Geisler S, Johnsen H, Hastie T, Eisen MB, van de Rijn M, Jeffrey SS, et al: Gene expression patterns of breast carcinomas distinguish tumor subclasses with clinical implications. Proc Natl Acad Sci USA 98: 10869-10874, 2001.

7. Sorlie T, Tibshirani R, Parker J, Hastie T, Marron JS, Nobel A, Deng S, Johnsen H, Pesich R, Geisler S, et al: Repeated observation of breast tumor subtypes in independent gene expression data sets. Proc Natl Acad Sci USA 100: 8418-8423, 2003.

8. Carey LA, Perou CM, Livasy CA, Dressler LG, Cowan D, Conway K, Karaca G, Troester MA, Tse CK, Edmiston S, et al: Race, breast cancer subtypes, and survival in the Carolina Breast Cancer Study. JAMA 295: 2492-2502, 2006.

9. Cheang MC, Chia SK, Voduc D, Gao D, Leung S, Snider J, Watson M, Davies S, Bernard PS, Parker JS, et al: Ki67 index, HER2 status, and prognosis of patients with luminal B breast cancer. J Natl Cancer Inst 101: 736-750, 2009.

10. Feeley LP, Mulligan AM, Pinnaduwage D, Bull SB and Andrulis IL: Distinguishing luminal breast cancer subtypes by $\mathrm{Ki67}$, progesterone receptor or TP53 status provides prognostic information. Mod Pathol 27: 554-561, 2014.

11. Yang XR, Sherman ME, Rimm DL, Lissowska J, Brinton LA, Peplonska B, Hewitt SM, Anderson WF, Szeszenia-Dabrowska N, Bardin-Mikolajczak A, et al: Differences in risk factors for breast cancer molecular subtypes in a population-based study. Cancer Epidemiol Biomarkers Prev 16: 439-443, 2007.

12. Spitale A, Mazzola P, Soldini D, Mazzucchelli L and Bordoni A: Breast cancer classification according to immunohistochemical markers: Clinicopathologic features and short-term survival analysis in a population-based study from the South of Switzerland. Ann Oncol 20: 628-635, 2009.

13. Vallejos CS, Gómez HL, Cruz WR, Pinto JA, Dyer RR, Velarde R, Suazo JF, Neciosup SP, León M, de la Cruz MA, et al: Breast cancer classification according to immunohistochemistry markers: Subtypes and association with clinicopathologic variables in a peruvian hospital database. Clin Breast Cancer 10: 294-300, 2010

14. Hammond ME, Hayes DF, Dowsett M, Allred DC, Hagerty KL, Badve S, Fitzgibbons PL, Francis G, Goldstein NS, Hayes M, et al: American Society of Clinical Oncology/College Of American Pathologists guideline recommendations for immunohistochemical testing of estrogen and progesterone receptors in breast cancer. J Clin Oncol 28: 2784-2795, 2010.

15. Wolff AC, Hammond ME, Schwartz JN, Hagerty KL, Allred DC, Cote RJ, Dowsett M, Fitzgibbons PL, Hanna WM, Langer A, et al; American Society of Clinical Oncology/College of American Pathologists: American Society of Clinical Oncology/College of American Pathologists guideline recommendations for human epidermal growth factor receptor 2 testing in breast cancer. Arch Pathol Lab Med 131: 18-43, 2007.

16. Bastien RR, Rodríguez-Lescure Á, Ebbert MT, Prat A, Munárriz B, Rowe L, Miller P, Ruiz-Borrego M, Anderson D, Lyons B, et al: PAM50 breast cancer subtyping by RT-qPCR and concordance with standard clinical molecular markers. BMC Med Genomics 5: 44, 2012.

17. Chu KC and Anderson WF: Rates for breast cancer characteristics by estrogen and progesterone receptor status in the major racial/ethnic groups. Breast Cancer Res Treat 74: 199-211, 2002.

18. Carvalho FM, Bacchi LM, Pincerato KM, Van de Rijn M and Bacchi CE: Geographic differences in the distribution of molecular subtypes of breast cancer in Brazil. BMC Womens Health 14: 102, 2014.

19. Meijer SL, Wesseling J, Smit VT, Nederlof PM, Hooijer GK, Ruijter H, Arends JW, Kliffen M, van Gorp JM, Sterk L, et al: HER2 gene amplification in patients with breast cancer with equivocal IHC results. J Clin Pathol 64: 1069-1072, 2011.

20. Alarcon-Rozas AE, Cueva MR, Galarreta J, Torres J, Gonzales E and Ramirez J: Features of recurrence of triple-negative (TN), non-metastatic breast cancer (NMBC) patients: A single institution study. J Clin Oncol 29: abstr 180, 2011.

21. Camejo N, Gonzalez V, Castillo C, Delgado L, Ferrero L, Fresco R, Santander GK, Aguiar S, Heinzen S, Martinez A, Meyer C, Sena G, Spera G, Ubillos L, Xavier F, Rodriguez R, Sabini G. Survival analysis of breast cancer subtypes assessed by hormone receptors and HER2 tumor expression in Uruguayan women with operable breast cancer. J Clin Oncol 29: e21064, 2011. 
22. Abuchacra LD, Alvarado GJ, Ferretti CN, Gómez AL, Hernández PA, Sánchez N and Sidan MJ: Relación entre la clasificación según tipos histológicos y subtipos moleculares más frecuentes de carcinoma mamario entre los años 2007 y 2012 en San Miguel de Tucumán, Argentina. CIMEL 17: 76-91, 2012.

23. de Macêdo Andrade AC, Ferreira Júnior CA, Dantas Guimarães B Pessoa Barros AW, Sarmento de Almeida G and Weller M: Molecular breast cancer subtypes and therapies in a public hospital of northeastern Brazil. BMC Womens Health 14: 110, 2014.

24. Martinez ME, Wertheim BC, Natarajan L, Schwab R, Bondy M, Daneri-Navarro A, Meza-Montenegro MM, Gutierrez-Millan LE, Brewster A, Komenaka IK, et al: Reproductive factors, heterogeneity, and breast tumor subtypes in women of mexican descent. Cancer Epidemiol Biomarkers Prev 22: 1853-1861, 2013.

25. Perez Sánchez V, Maldonado-Mtz HA, De León Trenado D, Bargalló Rocha E, Stankov Dragan A, Alvarado Miranda A, Ojeda Gaona A and Lara Medina F: Breast Carcinoma in Mexican Women, Molecular Subtypes Using Immunohistochemical Surrogate Markers E. J Cancer 14 (S1): 2012. Abstract 181.
26. Smith RA, Andrews K, Brooks D, DeSantis CE, Fedewa SA, Lortet-Tieulent J, Manassaram-Baptiste D, Brawley OW and Wender RC: Cancer screening in the United States, 2016: A review of current American Cancer Society guidelines and current issues in cancer screening. CA Cancer J Clin 66: 96-114, 2016. 